pÿEvaluating bicyclists risk perception using video clips :

Comparison of frequent and infrequent city cyclists

\title{
Lehtonen, Esko
}

2016-08

Lehtonen , E , Havia , V , Kovanen , A , Leminen , M \& Saure , E 2016 , ' Evaluating pÿbicyclists risk perception using video clips : Comparison of frequent and infrequent city cyclists ' , Transportation Research. Part F: Traffic Psychology and Behaviour , vol. 41, pp. 195-203 . https://doi.org/10.1016/j.trf.2015.04.006

http://hdl.handle.net/10138/167651

https://doi.org/10.1016/j.trf.2015.04.006

acceptedVersion

Downloaded from Helda, University of Helsinki institutional repository.

This is an electronic reprint of the original article.

This reprint may differ from the original in pagination and typographic detail.

Please cite the original version. 


\title{
Evaluating bicyclists' risk perception using video clips: comparison of frequent and infrequent city cyclists
}

\author{
Esko Lehtonen ${ }^{1}$, Ville Havia ${ }^{1}$, Anna Kovanen ${ }^{1}$, Miika Leminen $^{2,3}$, Emma Saure $^{1}$ \\ ${ }^{1}$ Traffic Research Unit, Institute of Behavioural Sciences, University of Helsinki, Finland \\ ${ }^{2}$ Cognitive Brain Research Unit, Cognitive Science, Institute of Behavioural Sciences, \\ University of Helsinki, Finland \\ ${ }^{3}$ MINDLab, Center of Functionally Integrative Neuroscience, Department of Clinical \\ Medicine, Aarhus University, Denmark
}

Corresponding author

Esko Lehtonen

esko.lehtonen@helsinki.fi

+358294129421

NOTICE: This is the author's version of a work that was accepted for publication in Transportation Research Part F: Traffic Psychology and Behaviour. Changes resulting from the publishing process, such as peer review, editing, corrections, structural formatting, and other quality control mechanisms may not be reflected in this document. Changes may have been made to this work since it was submitted for publication. A definitive version was subsequently published in http://dx.doi.org/10.1016/j.trf.2015.04.006 


\begin{abstract}
Hazard and risk perception has been studied extensively among car drivers, and their link to crash involvement is established. Bicyclists, in particular, are vulnerable road users. Better understanding of their risk and hazard perception could help to improve their traffic safety.

In this study, we investigated the risk perception of bicyclists in a city environment. Two groups of bicyclists were compared: 19 frequent and 19 infrequent bicyclists. Participants were shown video clips taken with a camera attached to the handlebar of a bicycle, and they were asked to continuously indicate with a slider how much caution the situation needed.

The frequent cyclists had more frequent rises in the caution estimate, which suggest that they anticipated or detected more hazards than infrequent cyclists. This is in line with the classical hazard perception results, which link the car driving experience to faster and more accurate hazard perception. The overall level or caution was not directly related to the rise event rate or bicycling frequency. Those cyclists who reported typically cycling faster than others showed elevated overall level of caution on sidewalks compared with others, but there was no difference on bike paths.
\end{abstract}

\title{
Keywords
}

bicyclist, risk perception, hazard perception, cycling experience, vulnerable road users

\section{Highlights}

Bicyclists rated the level caution continuously while watching video clips.

Frequent and infrequent bicyclists were compared.

Frequent bicyclists had higher number of caution estimate rises.

Overall level of caution was not directly related to rises.

Overall level of caution was elevated for fast bicyclists on sidewalks. 


\section{Introduction}

Bicycling is an important form of transportation that is gaining more popularity in Europe and in the Northern America (Pucher, Buehler \& Seinen, 2011). Promoting bicycling as a form of transportation has been taken as an agenda for transportation policy, because cycling is seen as environmentally friendly and is good for public health (Andersen, Schnohr, Schroll \& Hein, 2000; de Hartog, Boogaard, Nijland \& Hoek, 2010). However, as bicycling becomes more popular, bicycling crashes and fatalities also increase due to increased exposure. Among car drivers, good hazard perception skills are recognized as important for crash avoidance. Consequently, methods to evaluate them have been developed during the last 40 years (Pelz \& Krupat, 1974; Quimby et al., 1986; McKenna \& Crick, 1994; for review see Deery, 1999; Underwood, 2007). Given bicyclists' physical vulnerability, it could be argued that it is important to develop methods to evaluate their risk and hazard perception skills (see Horswill \& Helman, 2003, for a similar argument regarding motorcyclists).

In hazard perception studies, a traffic situation is presented either with still images, video, or an interactive driving simulator, and the participants are asked to respond to hazards they detect. Typically, the number of hazards reported or hazards looked are used as measures (e.g. McKenna \& Crick, 1994; Sagberg \& Bjørnskau, 2006; Wetton \& Horswill, 2011; Crundall et al. 2012; Meir, Borowsky \& Oron-Gilad, 2014). A related but separate research tradition has focused on risk perception (Slovic, Fischhoff \& Lichtenstein, 1980). Risk is the probability of some typically adverse outcome, and risk perception is formation of a subjective estimate for the magnitude of the risk (Slovic et al., 1980). In the context of traffic, risk can be understood to be the probability of a crash.

While the focus of the hazard perception studies is to investigate how well the participants anticipate and detect hazardous events, the risk perception studies focus on the assessment of the level of risk in a situation overall. However, hazard and risk perception paradigms can be thought to overlap in studies where a continuous rating of risk is used to evaluate dynamically evolving traffic situations (e.g. Pelz \& Krupat, 1974; Ahopalo, Lehikoinen \& Summala, 1987). When the participants are asked to report the current level of risk with a continuous estimate, the rises in the estimate can be thought to reflect anticipation of potential hazards or detection of imminent hazards (Pelz \& Krupat, 1974; Ahopalo, Lehikoinen \& Summala, 1987). The risk level is likely rated high as long as a hazard or hazardous situation is present.

\subsection{The effect of experience on hazard and risk perception}

Experienced car drivers have a lower risk of traffic accidents compared with inexperienced drivers (McKnight \& McKnight, 2002). This is often attributed to experienced drivers' better hazard perception skills (Quimby et al. 1986; McKenna \& Crick, 1994). Good hazard perception skills help to anticipate and detect hazards earlier, which gives more time to avoid a crash (Pelz \& Krupat, 1974; Ahopalo, Lehikoinen \& Summala, 1987; McKenna \& Crick, 1994). Hazard perception skills are composed of the ability to use 
cues or precursors to predict what will happen next (Jackson, Chapman \& Crundall, 2009) and to scan efficiently for relevant targets (Crundall \& Underwood, 1998; Wikman, Nieminen \& Summala, 1998; Falkmer \& Gregersen, 2005; Borowsky, Shinar, Oron-Gilad, 2010). In other words, hazard perception skills are important for drivers' situation awareness (Endsley, 1995; Horswill \& McKenna, 2004).

Perception of risk is often thought to have an important role in the self-regulation of driving, however, theoretical models differ in the exact mechanism (Taylor, 1964; Näätänen \& Summala, 1976; Wilde, 1984; Fuller, 2005; Summala, 2007). In this study, we use self rated continuous estimate of caution, which can be interpreted as a cognitive estimate for the perceived level of risk. In risk adjustment theories, the level of perceived risk is central for the control of behaviour (Taylor, 1964). In zero-risk models, the risk is seen as a feedback for safety margin violations (Näätänen \& Summala, 1976; Summala, 2007). From perspective of zero-risk models, which suggest that actual experienced of risk are rather rare, a self rated continuous estimate of caution can be interpreted to reflect the effort required to maintain the safety margins. However, in both cases it can be assumed that a high level of caution may be associated with behavioral adaptation, which aims to reduce the actual level of risk, i.e., the probability to become involved in a crash.

Video based risk estimates of traffic environments appear to be comparable to actual risks (Charlton, Starkey, Perrone \& Isler, 2014), but experience modifies the perception of the risk to self. Safer drivers estimate the caution needed in traffic greater compared with drivers involved in crashes (Pelz \& Krupat, 1974). Younger and less experienced drivers tend to have an illusion of invulnerability (Matthews \& Moran, 1986). They estimate their own risk as comparable to older, experienced drivers, even though they recognize that their peers have a higher risk. Their risk estimates become more realistic after involvement in a crash.

Risk and hazard perception is not much studied among bicyclists using video clips (but see Parkin, Wardman \& Page, 2007; Vansteenkiste, Linus, Greet \& Lenoir, 2013). However, it is likely that the bicycling experience improves hazard perception and increases the risk estimates in a bicycling context.

\subsection{The present study}

The first goal of this study was to explore the methodology to investigate bicyclists' risk perception with realistic but well controlled stimuli. We used video clips from natural situations, filmed from the bicyclists' perspective. Participants watched the video clips, and they were asked to continuously indicate with a slider how much caution the situation needed.

The second goal was to compare frequent and infrequent city bicyclists' risk perception. Two contrasting hypotheses can be presented regarding the effect of cycling frequency on the overall level of caution. First, repeated exposure to a risk may lead to desensitization and consequently lower overall level of caution. For example, Møller and Hels (2008) studied cyclists' risk perception in roundabouts. The 
cyclists who often cycled through the roundabout perceived the crash risk lower than the cyclists who seldom passed through the roundabouts.

On the other hand, frequent cyclists' greater experience should make them able to anticipate and detect more hazards compared with novice cyclists (McKenna \& Crick, 1994; Wallis \& Horswill, 2007; Crundall et al. 2012). A rise in the caution estimate is likely produced when a hazard is detected or only anticipated (e.g. scanning for potential hazards in an intersection). Consequently, the experienced cyclists should have more rises in the continuously estimated level of caution. If the overall level of risk is based on the number of hazards perceived, then the experienced cyclists should also have a higher overall level of caution.

The use of the continuous estimate also makes it possible to investigate response pattern, especially the speed (i.e. slope) of the rises. With experience, the cyclists' situational awareness could improve (Horswill \& McKenna, 2004; Underwood, 2007; Endsley, 1995). This could manifest in faster rises in frequent bicyclists, as a steep rise probably indicates a certain identification of a possible or present hazard, while gradual or slow rise indicates a more uncertain assessment of hazard.

Video clips were selected by the researchers from video footage of normal, everyday cycling of one of the researchers (ES). The clips depicted mainly situations from sidewalks and bike paths. For the analysis of the data, we classified the video clips to these two categories in order to investigate how the environment would affect the risk estimates differently for sidewalks and bike paths. 


\section{Methods}

\subsection{Participants}

A group of frequent and infrequent bicyclists were recruited through university email lists and Helsinki Cyclists association. Twenty-one frequent and nineteen infrequent city cyclists participated the experiment, but two frequent cyclists were excluded based on the pre-experiment questionnaire. Their weekly and annual cycling kilometers were much lower than rest of the frequent cyclists (Fig. 1).

Frequent cyclists ( $n=19,10$ female) had cycled at least once a week in the city center or the surrounding urban area of Helsinki (mainly consisting of city blocks with multistory houses) (Table 1) and their weekly cycling distance was at least 20 kilometers during their biking season over the last two years. Their annual cycling distance was at least 500 kilometers, and most of them had cycled over 1000 kilometers. Infrequent cyclists ( $n=19,15$ female) rode less frequently than once in a month (Supplementary Table 1 ) and had never cycled actively in the city center or surrounding urban area of Helsinki. They cycled 0-10 kilometers per week and their annual cycling distance was less than 100 kilometers.

Frequent cyclists reported that they typically cycle faster than other cyclists (Table 2) and their biking seasons were longer than infrequents' (Supplementary Table 1,2). Frequent cyclists had had more cycling accidents like falling and collision with other cyclists, pedestrians and cars compared with infrequents (Supplementary Table 3).

In the post-experiment questionnaire, 18 out of 19 frequent cyclists reported that they had "cycled often" on the routes depicted on the videos, but only 1 out of 19 infrequent cyclists reported that. Frequent cyclists were older (23-67 years, $M=36$ years, $S D=14.7$, median=32) than infrequent cyclists (20-45, M=25, SD=5.8, median=23).

Table 1. Frequent and infrequent cyclists' average amount of cycling in the center of Helsinki and in the surrounding urban area.

\author{
How often you cycle \\ Less than once a month \\ Once a month \\ More than once a month \\ Once a week \\ More than once a week
}

$\begin{array}{ll}\text { Frequent } & \\ \text { Center } & \text { Urban } \\ 1 & 0 \\ 0 & 0 \\ 3 & 0 \\ 1 & 3 \\ 14 & 16\end{array}$

$\begin{array}{ll}\text { Infrequent } & \\ \text { Center } & \text { Urban } \\ 18 & 18 \\ 1 & 1 \\ 0 & 0 \\ 0 & 0 \\ 0 & 0\end{array}$


Table 2. Frequent and infrequent cyclists' cycling speed compared to other cyclists.

$\begin{array}{lll}\text { "I cycle slower "I cycle at the same "I cycle faster } & \\ \text { than others" } & \text { speed than others" } & \text { than others" }\end{array}$

$\begin{array}{llll}\text { Frequent } & 0 & 8 & 11 \\ \text { Infrequent } & 8 & 10 & 1\end{array}$

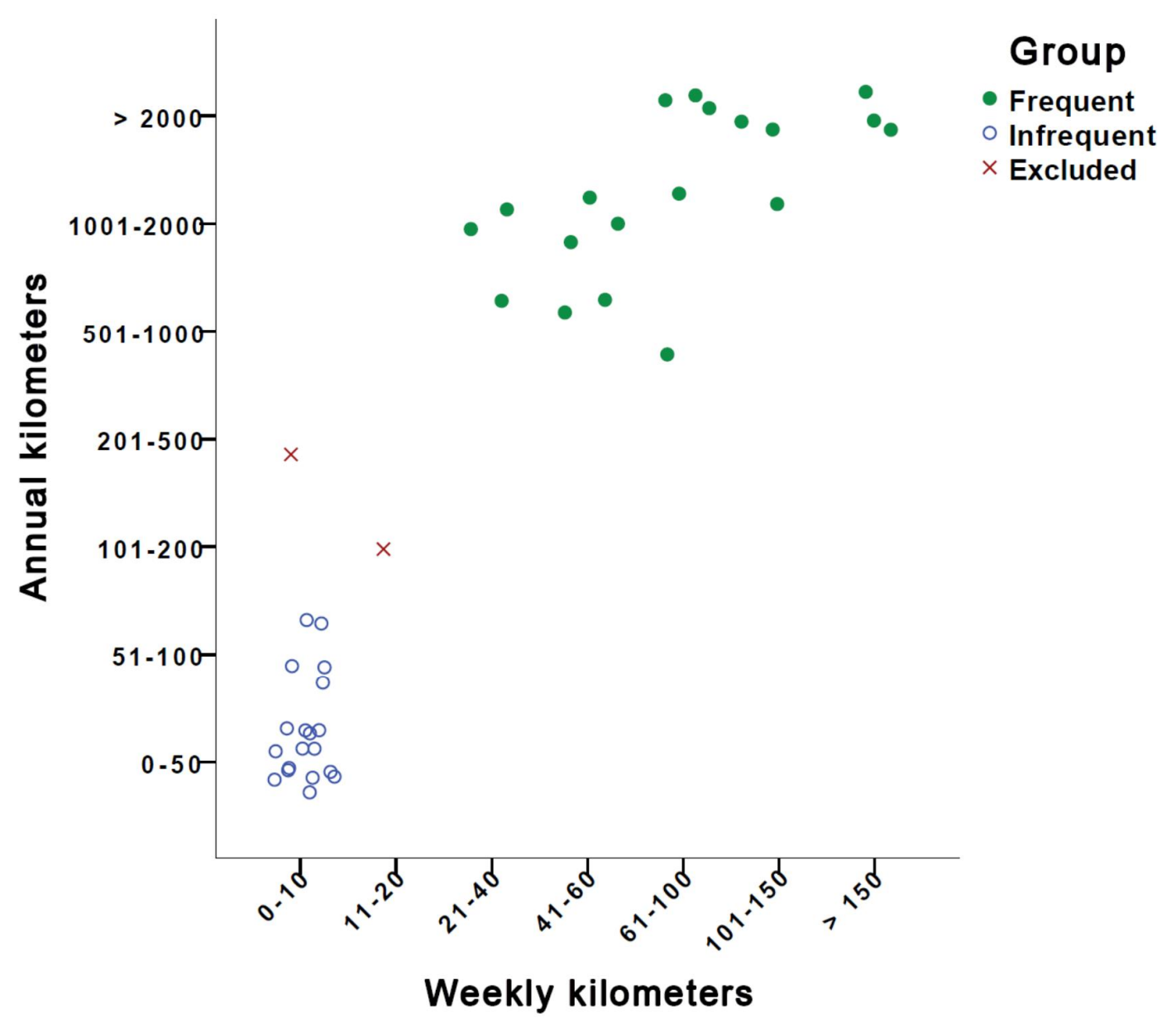

Fig. 1. Frequent and infrequent cyclists' average cycling distance per annum and per week during their cycling season. The categorical values have been jittered for display. Excluded participants are marked with crosses. 


\subsection{Stimuli}

Stimuli consisted of 65 video clips with durations between 6 and 41 seconds (mean=18). Video clips were selected from video footage of everyday cycling in Helsinki filmed by one of the authors (ES) in the autumn of 2012. Videos were filmed using a GoPro Hero HD1 (GoPro, Inc., USA) camera attached to the handlebar of a bicycle at height of $110 \mathrm{~cm}$ from ground. This was to ensure that the clips would be filmed from the cyclists' perspective. The video clips were presented on a 22" screen with a resolution of $1650 \times 1050$. The screen was at about $60 \mathrm{~cm}$ distance from the participant's eyes. All video clips were scaled to size $1024 \times 768$, and were presented in the middle of the screen.

Video clips were classified based on environment (bike path vs. sidewalk) because environment seemed relevant to risk evaluation based on participants' answers in the post-experiment questionnaire. The classification was done after starting the experiment but before the analysis of results. There were 40 video clips filmed on the bike path and 15 video clips filmed on the sidewalk. 10 video clips were excluded from the analysis either because they were filmed on a roadway or contained a mix of environments.

The study was designed in order to be able to compare participant's eye movements when viewing video clips with and without the caution estimation task. Therefore the video clips were divided pseudo randomly into two sets. Each participant viewed one set with the caution estimation task and another one without performing the task. The order of sets and tasks were balanced within and between groups. Unfortunately, due to unexpected malfunction of the camera the eye movement data could not be used and are not reported here.

\subsection{Procedure}

Participants gave informed consent to participate in this study, and they were rewarded with a movie voucher afterwards. The participants were first asked to fill an electronic background questionnaire before the actual experiment.

In the experiment, the participants watched video clips of cycling and were asked to imagine being the bicyclist depicted. They were asked to continuously indicate with a slider how great caution they felt the situation demanded in order to avoid a crash. Before the clips, a practice clip was shown so that the participant could become accustomed to the use of the slider. Between the clips was a short break. After the experiment, participants filled a post-questionnaire. The length of the experiment was about one hour in total, and watching the video clips took about 30 minutes.

A custom made slide potentiometer was used to measure participants' evaluation of caution level. The distance from lowest position to the highest position was $60 \mathrm{~mm}$. The scale was indicated by " 0 " in the lowest point, " 50 " in the middle position and " 100 " in the top position. The position of the slider was converted to the linear scale of 0-100 (0="no caution", 100="maximal caution"). The slider was 
positioned on the table in comfortable location and the longitudinal axis of slider was pointing forwards. The slider position was digitized and recorded as a voltage signal with NI USB-6343 data acquisition board (National Instruments Co, USA) and custom made LabView software (version 9.0, National instruments (o, USA) with sampling rate of $50 \mathrm{~Hz}$. Nonlinear voltage signal was digitally transformed to the aforementioned linear scale. The transformation was found empirically.

\subsection{Data processing}

The slider data were filtered first using a median filter (window=3) to remove noise, then using SavitzkyGolay's smoothing filter (window=3, degrees $=2$ ). The first 200 recorded values $(4 s)$ in the beginning of each clip were left out of all analyses, so that the initial rise of the slider to the base level would not be included. All cases ( 3 of 1045) where the participant failed to finish the clip (e.g. due to pressing a button on the keyboard by mistake) were left out of analyses.

The caution level, rise rate and rise speed parameters were calculated. The caution level for each video clip was parameterized as the median position of the slider during the examined part of the clip. Rise rate was calculated by first identifying all substantial rises of slider position using the following criteria: if each value in the section was greater than the preceding value and if the difference of the last and first value of the section was greater than 2 scale points. Then, the amount of rise events was divided by a length of the video clip in seconds. Thus the rise rate parameter indicated an average amount of rise events per second.

For all substantial rises, the rise speed was defined as the quotient of its magnitude and duration. Magnitude was defined as the difference between the last and the first value of the rise, and duration as its length in seconds. 


\section{Results}

For the analysis, the caution level, rise rate and rise speed values were first normalized using base 10 logarithm. Then, each participant's average over the clips was calculated and used in the statistical tests.

The frequent and infrequent bicyclists groups were compared with Welch two sample t-test, which allows different variance for the samples. The average values were also calculated separately for bike path and sidewalk video clips per participant. Because each participant had two observations, the data were analyzed using a mixed effects model with group (frequent vs. infrequent) and environment (bike path vs. sidewalk) fixed effects and participant as a random effect. The mixed effects model yields results comparable to traditional repeated measures ANOVA, but had an advantage of producing the coefficients for the model as in regression analysis. In contrasts, infrequent and bike path were the baselines. Significance level of 0.05 was used.

\subsection{Overall caution level}

The overall caution levels between frequent and infrequent groups were not significant $(t(33.41)=-0.31$, $p=0.76)$. The effect of group was not significant in the mixed model either $\left(X^{2}(4)=0.76, p=0.38\right)$, but the effect of environment $\left(X^{2}(5)=25.41, p<0.01\right)$ and the interaction of group and environment were significant $\left(X^{2}(6)=11.13, p<0.01\right)$.

Contrasts showed that clips filmed on the sidewalk had significantly higher level of caution than on the bike paths $(b=0.065, \mathrm{SE}=0.028, \mathrm{t}(35)=2.32, \mathrm{p}=0.03)$. Most importantly, the interaction of group and environment was significant, indicating that on sidewalks, the caution estimate is elevated for frequent cyclists but not for infrequent $(b=0.1387, S E=0.040, t(36)=3.50, p<0.01)$. (Fig. 2).

These results can be interpreted to be linked to the typical speed used. In the background questionnaire, we asked the participants to characterize their typical cycling speed relative to other cyclists with three levels: slower, equal or faster. All but one cyclist who had reported cycling faster were frequent cyclists, and all in the slower group were infrequent cyclists. The cycling speed alone did not have a significant effect $\left(X^{2}(5)=3.24, p=0.20\right)$. When the interaction of the typical cycling speed and the environment was analyzed using a mixed model, the interaction was significant $\left(X^{2}(8)=7.13, p=0.03\right)$. The contrasts showed that on sidewalks, it was the faster group $(b=0.122, \mathrm{SE}=0.049, \mathrm{t}(35)=2.51, p<0.02)$ who had the greater caution level relative to the equal group, and the slower group did not differ from the equal group $(b=-0.001, S E=0.055, t(35)=-0.01, p=0.99)$. (Fig. 3) 


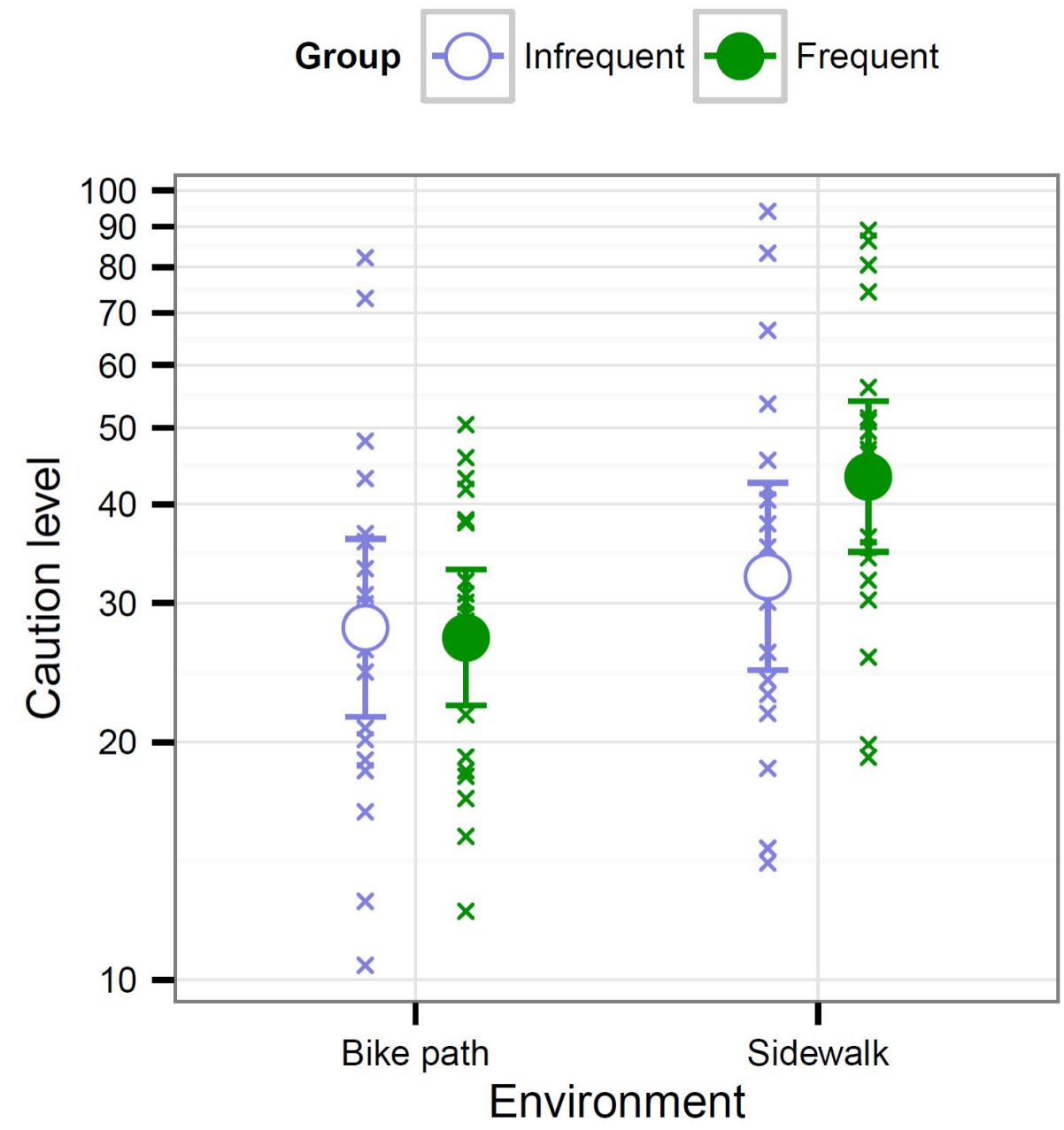

Fig. 2. Overall level of caution for frequent and infrequent cyclists on bike paths and sidewalks. The figure shows means and their $95 \%$ confidence intervals, calculated from log 10 transformed values. Individual data points are marked with crosses. 


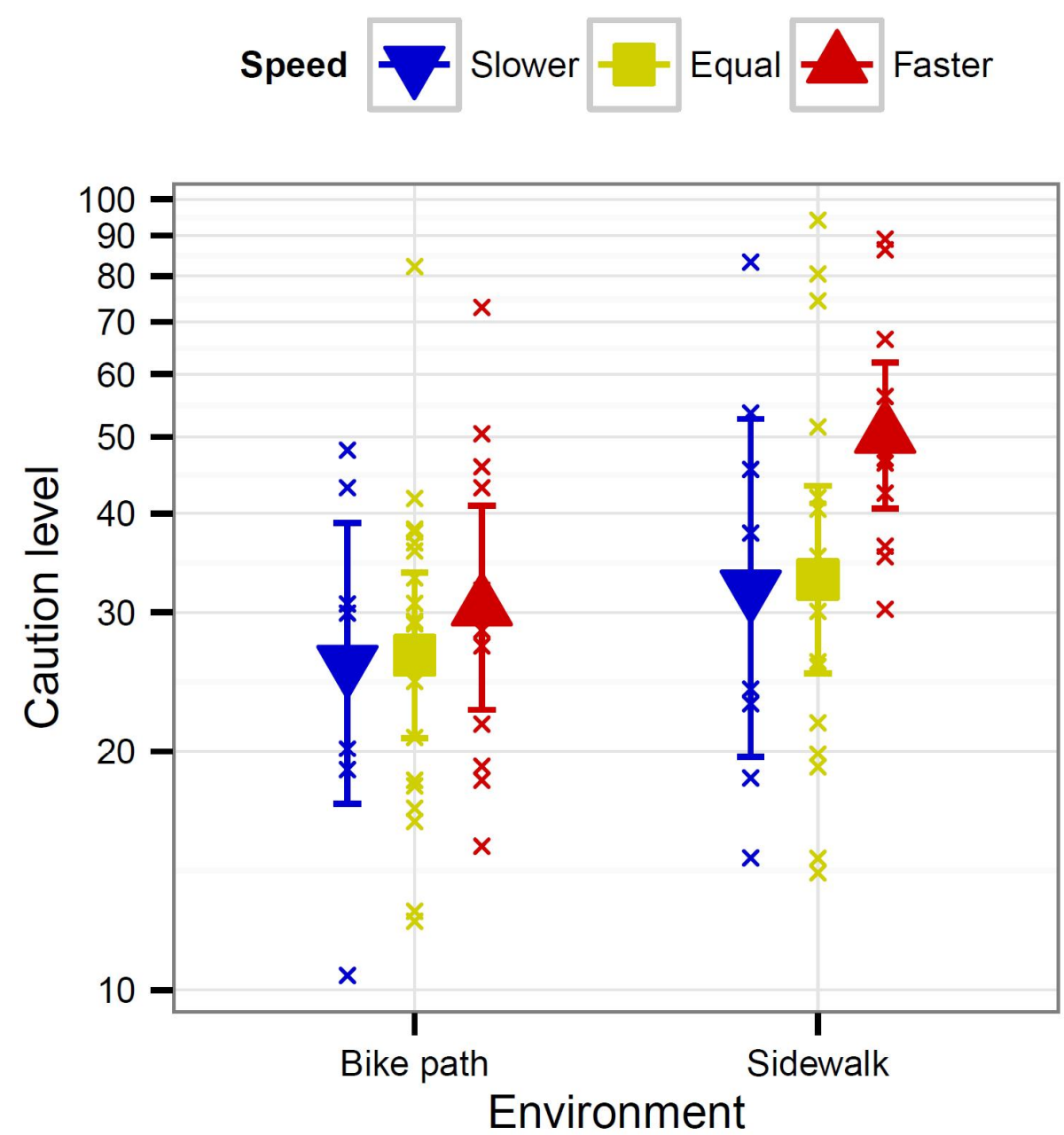

Fig. 3. Overall level of caution as a function of environment and self-reported cycling speed compared with other bicyclists. The figure shows means and their $95 \%$ confidence intervals, calculated using log10 transformed values. Individual data points are marked with crosses. 


\subsection{Caution rise rate}

Frequent bicyclists had a significantly higher average rise rate compared with infrequent bicyclists $(t(31.47)=-2.35, p=0.03$, frequent $M=0.18$ rise $/ \mathrm{s}$, infrequent $M=0.21$ rise $/ \mathrm{s})$. The effects of group $\left(X^{2}(4)\right.$ $=3.85, p=0.0498)$ and environment $\left(X^{2}(5)=37.82, p<0.01\right)$ were included to the mixed model. Their interaction was only marginally significant $\left(X^{2}(6)=0.02, p=0.88\right)$. In contrasts analysis with the main effects in the model, frequent cyclists had a higher rate than infrequent $(b=0.0,069, \mathrm{SE}=0.030, t(36)=$ $2.26, p=0.30)$ and sidewalks had a higher rate than bike paths $(b=0.187, \mathrm{SE}=0.025, t(37)=7.45, p<$ 0.01). (Fig. 4)

The effect of cycling speed and its interaction with the environment were also investigated with a mixed model. The effect of cycling speed was not significant $\left(X^{2}(5)=1.15, p=0.56\right)$, nor the interaction $\left(X^{2}(8)=\right.$ $0.18, p=0.91$.

\subsection{Rise speed}

Frequent cyclists' rise speeds were not significantly different from the infrequent cyclists' $(\mathrm{t}(36.00)=-$ $1.583, p=0.12)$. In a mixed model, the effect of environment was significant $\left(X^{2}(5)=9.35, p=0.02\right)$. The effect of group was marginally significant $\left(X^{2}(4)=3.18, p=0.07\right)$ as well as the interaction $\left(X^{2}(6)=2.85, p\right.$ $=0.09$ ). Using the model without the marginally significant interaction term, the environment contrast showed that rises were significantly faster on sidewalks $(b=0.058, S E=0.018, t(37)=3.19, p<0.01)$ (Fig. $5)$.

The effect of cycling speed and its interaction with the environment were also investigated with a mixed model. The effect of cycling speed was not significant $\left(X^{2}(5)=1.11, p=0.57\right)$, nor the interaction $\left(X^{2}(8)=\right.$ $0.15, p=0.92$ ). 


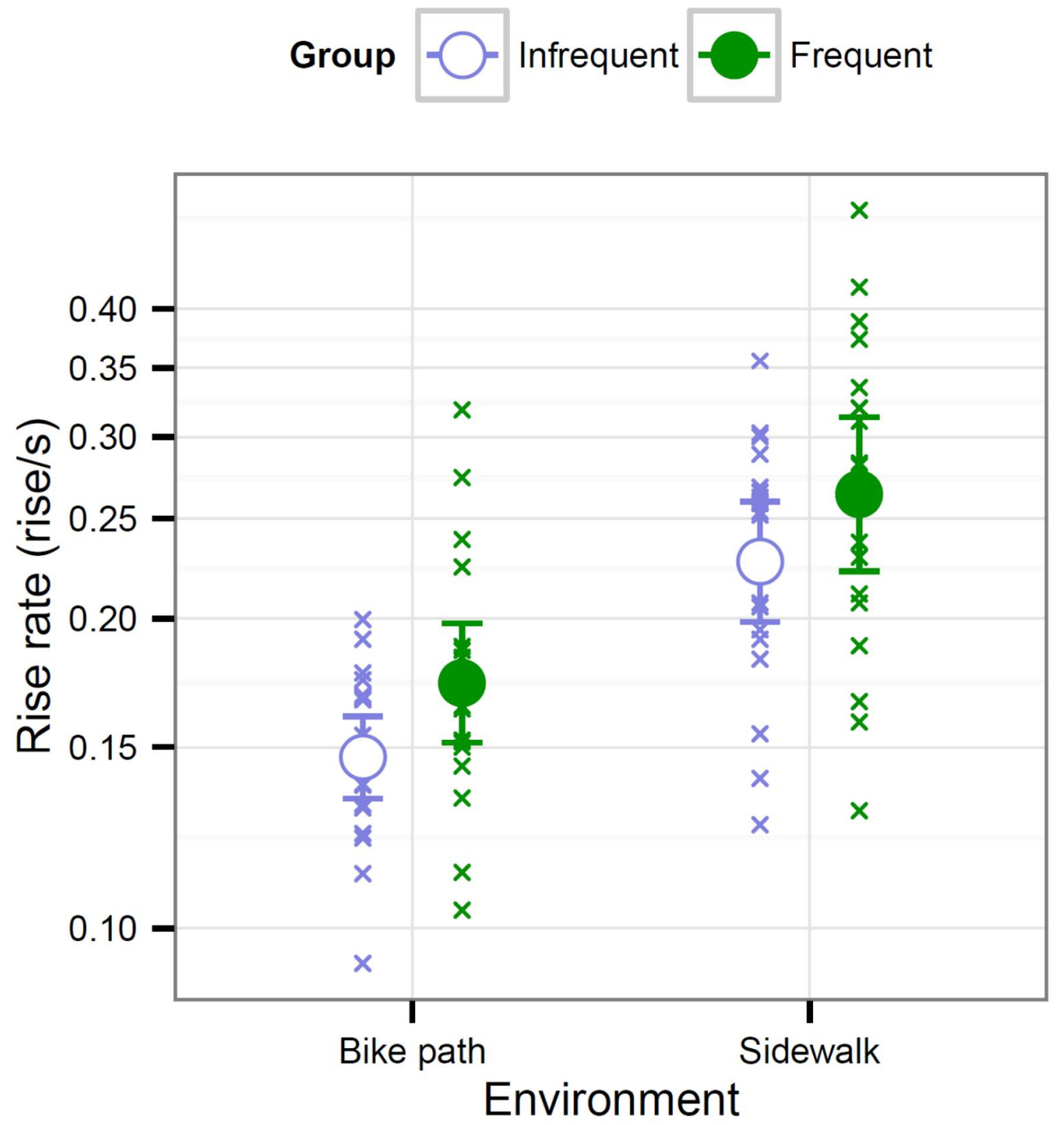

Fig. 4. Average caution rise rate for frequent and infrequent bicyclists on bike paths and sidewalks. The figure shows means and their $95 \%$ confidence intervals, calculated using log 10 transformed values. Individual data points are marked with crosses. 


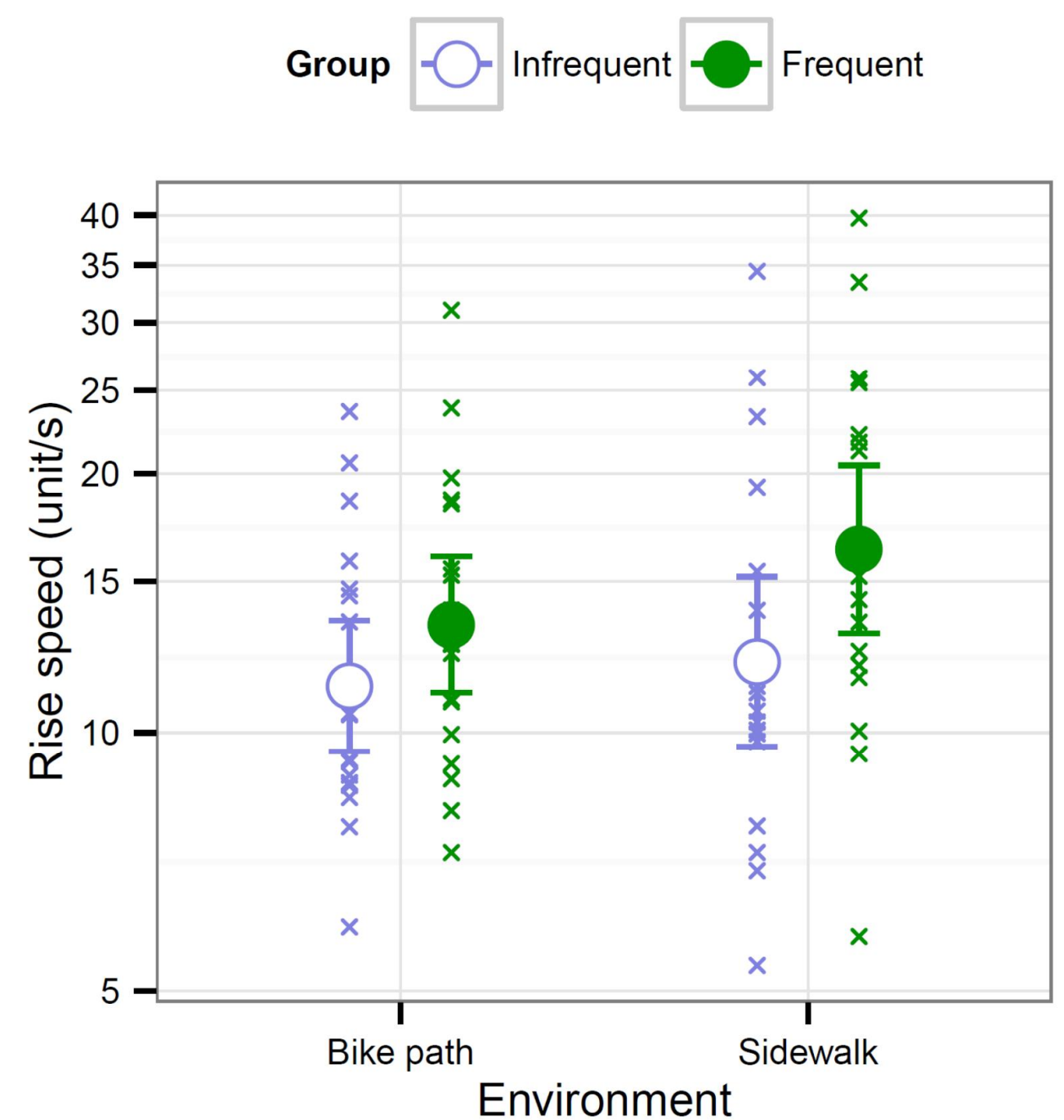

Fig. 5. Average caution rise speeds (scale units per second) for frequent and infrequent bicyclists on bike paths and sidewalks. The figure shows means and their $95 \%$ confidence intervals, calculated using log10 transformed values. Individual data points are marked with crosses. 


\section{Discussion}

The first measure investigated was the level of cognitive estimate of risk, which was measured using overall level of caution. The frequent and infrequent cyclists did not differ in their overall level of caution averaged over the clips. However, when the bike path and sidewalk clips were averaged separately, the interaction of the corresponding environment factor and the bicyclists group was significant. The interaction indicated that the frequent group had significantly higher overall level of caution on sidewalks compared with infrequent cyclists, but there was no difference on bike paths. Overall caution levels suggest that frequent cyclists would not be desensitized to risks, because their levels were similar to infrequent ones on both the bike paths and sidewalks.

The second measure was the rise rate, the average number of caution estimate rises per a second. Rise events can be understood to reflect anticipation of potential or detection of imminent hazards. Regarding this measure, the frequent bicyclists had significantly larger rate than infrequent bicyclists. For both groups, sidewalks had higher caution rise rate than the bike paths. This probably reflects the fact that sidewalks are typically more demanding environments for a relatively fast moving vehicle like a bicycle. The results are in line with the previous studies among car drivers, which have shown that experienced car drivers detect hazards earlier and in greater number than novice car drivers (Quimby et al., 1986; McKenna \& Crick, 1994; Crundall et al., 2012). Of course, the rise events are not directly comparable to discrete responses given in a hazard perception test, because a single hazard may evoke multiple rise events, for example.

The overall caution levels were not directly related to the caution rise intervals. In contrast to what would be expected if overall caution level reflects the ability to spot hazards, more frequent bicyclists had a higher caution rise rate overall, but their overall caution level was significantly higher only on sidewalks. This suggests that overall level of caution is not based only on the number of hazards anticipated or detected, but is influenced by other factors.

With more experience, frequent cyclists are likely able to perceive the risks more accurately than less experienced infrequent cyclists (for similar results among car drivers, see Matthews \& Moran, 1986; Quimby et al., 1986; McKenna \& Crick, 1994). If we take the frequent cyclists overall level of caution as an estimate for the actual level of risk, then the conclusion would be that the infrequent, less experienced city cyclists underestimate the risks of cycling on the sidewalks. However, the current data suggest that it is necessary to more carefully investigate the relationship between cycling style and environment. We found that cyclists who reported that they typically cycle faster than other cyclists rated higher caution levels on sidewalks, and faster cyclists are primarily in the frequent cycling group. The cyclists reporting equal or slower speed did not have higher caution level on sidewalks.

Cycling fast on sidewalks can be demanding and have a higher risk of crashes because of smaller time and space margins compared with bike paths. Therefore, fast bicyclists may avoid the sidewalks because it is not a comfortable environment for them. Repeated exposure to a risk may also lead to 
desensitization (Møller \& Hels, 2008). In the current case, avoiding the sidewalks while cycling may have in opposite sensitized the fast cyclists to the risks. Unfortunately, in this study the cycling speed confounded with cycling frequency, and exposure to the sidewalks could not be determined.

The third measure was the speed of the caution estimate rises. We hypothesized that rise speed could be associated with experience, higher speed indicating higher degree of certainty. However, even though the group difference was in the expected direction, the difference was only marginally significant. The only significant difference was as a function of environment. The rises on the sidewalk were faster than on the bike paths. This may indicate that the sidewalk clips contained more quickly developing hazardous situations than the bike path clips.

In the future studies it would be good to control how accurately the participants were able to differentiate between sidewalks and bike paths and what were their attitudes regarding cycling on sidewalks. Cyclists over 12 years old should not cycle on sidewalks in Finland without a "compelling reason" to do so (Tieliikennelaki of 1981). The law is seldom enforced, and together with non-existence of bike paths and lanes in many streets, many adult cyclists use sidewalks occasionally instead of cycling on the roadway. Furthermore, in Helsinki, many bike paths are shared with pedestrians, especially outside the city center, rendering the distinction between sidewalks and bike paths sometimes vague. It is possible that the less experienced infrequent cyclists may have not understood the difference between bike paths and sidewalks in all of the clips. However, because the typical cycling speed appears to be better predictor for the overall caution level on sidewalks than the cycling frequency, it is unlikely that this has an important effect on the current results.

The video clips presented in the experiment were collected from normal bicycling by one of the researchers (ES), and did not contain extremely hazardous situations. It is often recognized that constructing a hazard perception test which reliably differentiates between novice and experienced drivers needs deliberate selection of stimuli either by expert panel (e.g. Wetton et al, 2011) or by using participants' reactions as indication of hazardous events (e.g. Meir et al., 2014). Despite the limitations of the current experiment, it is encouraging that the caution rise rate differentiated the two groups.

\subsection{Conclusion}

Bicyclist risk and hazard perception is not yet extensively studied using video clips from real bicycling. The present study demonstrates that such a paradigm has potential in bicycling research and that the measure of continuous caution estimate is promising.

The results suggests that differences in overall level of caution are a function of cycling speed and the environment. The overall level of caution was not directly related to the caution rise rate, which in the current study is the closest measure to the number of hazards anticipated and detected. This suggests that cognitively estimated level of risk and hazard perception are not directly related. 
The caution rise rate was higher for frequent cyclists, which suggests that experienced cyclists anticipated and detected more hazards than novices. The rise rate was also higher on sidewalks than on bike paths, which is in line with the general belief that sidewalks are more demanding and hazardous environments for bicyclists than bike paths.

\section{Acknowledgements}

We thank PhD Heikki Summala and PhD Otto Lappi for their invaluable comments and support to this work. Sanna Talola participated to the design and realization of the experiment. The comments from two anonymous reviewers greatly improved the manuscript. Caitlin Dawson and Leonardo Sorgi helped by proofreading the manuscript. Finnish Cultural Foundation is gratefully acknowledged for their support to the first author (grant no. 00130510). 


\section{References}

Ahopalo, P., Lehikoinen, A. \& Summala, H. (1987). Kuljettajien ajokokemus ja vaaratilanteiden havaitseminen (Driving experience and response latencies in hazard perception). Reports of Traffic Research Unit 12, Helsinki: University of Helsinki.

Andersen, L. B., Schnohr, P., Schroll, M. \& Hein, H. O. (2000). All-cause mortality associated with physical activity during leisure time, work, sports and cycling to work. Archives of Internal Medicine, 160, 16211628.

Borowsky, A., Shinar, D. \& Oron-Gilad, T. (2010). Age, skill, and hazard perception in driving. Accident Analysis and Prevention, 42, 1240-1249.

Charlton, S. G., Starkey, N. J., Perrone, J. A. \& Isler, R. B. (2014). What's the risk? A comparison of actual and perceived driving risk. Transportation Research Part F, 25, 50-64.

Crundall, D. E. \& Underwood, G. (1998). Effects of experience and processing demand on visual information acquisition in drivers. Ergonomics, 41, 448-458.

Crundall, D., Chapman, P., Trawley, S., Collins, L., van Loon, Editha, Andrews, B. \& Underwood, G. (2012). Some hazards are more attractive than others: Drivers of varying experience respond differently to different types of hazard. Accident Analysis and Prevention 45, 600-609.

Deery, H. A. (1999). Hazard and risk perception among young novice drivers. Journal of Safety Research, $30,225-236$.

Endsley, M. R. (1995). Toward a theory of situation awareness in dynamic systems. Human Factors, 37, 32-64.

Falkmer, T. \& Gregersen, N. P. (2005). A comparison of eye movement behavior of inexperienced and experienced drivers in real traffic environments. Optometry and Vision Science, 82(8), 732-739.

Fuller, R. (2005). Towards general theory of driver behaviour. Accident Analysis and Prevention, 37, 461472.

de Hartog, J. J., Boogaard, H., Nijland, H. \& Hoek, G. (2010). Do the health benefits of cycling outweigh the risk? Environmental Health Perspectives, 118, 1109-1116.

Horswill, M. S. \& Helman, S. (2003). A behavioural comparison between motorcyclists and a matched group of non-motorcycling car drivers: Factors influencing accident risk. Accident Analysis and Prevention, 35, 589-597. 
Horswill, M.S. \& McKenna, F.P. (2004). Drivers' hazard perception ability: Situation awareness on the road. In S. Banbury \& S. Tremblay (Eds.). A Cognitive Approach to Situation Awareness: Theory and Application (pp. 155-175). Hampshire: Ashgate.

Jackson, L., Chapman, P. \& Crundall, D. (2009). What happens next? Predicting other road users' behaviour as a function of driving experience and processing time. Ergonomics, 52(2), 154-164.

Matthews, M. L. \& Moran, A. R. (1986). Age difference in male drivers' perception of accident risk: The role of perceived driving ability. Accident Analysis \& Prevention, 18, 299-313.

McKenna, F. P. \& Crick, J. L. (1994). Hazard perception in drivers: a methodology for testing and training. TRRL Report CR313. Crowthorne: Transport and Road Research Laboratory.

McKnight, A. J. \& McKnight, A. S. (2002). Young novice drivers: careless or clueless? Accident Analysis and Prevention, 35, 921-925.

Meir, A., Borowsky, A. \& Oron-Gilad, T. (2014). Formation and evaluation of act and anticipate hazard perception training (AAHPT) intervention for young novice drivers. Traffic Injury Prevention, 15, 172-180.

Møller, M. \& Hels, T. (2008). Cyclists' perception of risk in roundabouts. Accident Analysis \& Prevention, 40, 1055-1062.

Näätänen, R. \& Summala, H. (1976). Road-user behaviour and traffic accidents. North-Holland Publishing Company.

Quimby, A. R., Maycock, G., Carter, L. D., Dixon, R. \& Wall, J. G. (1986). Perceptual abilities of accident involved drivers. TRRL Report RR27. Crowthorne: Transport and Road Research Laboratory.

Parkin, J., Wardman, M., \& Page, M. (2007). Models of perceived cycling risk and route acceptability. Accident Analysis and Prevention, 39, 364-371.

Pelz, D. C. \& Krupat, E. (1974). Caution profile and driving record of undergraduate males. Pergamon Press, 6, 45-58.

Pucher, J., Buehler, R. \& Seinen, M. (2011). Bicycling renaissance in North America? An update and reappraisal of cycling trends and policies. Transportation Research Part A: Policy and Practise, 45, 451475.

Sagberg, F. \& Bjørnskau, T. (2006). Hazard perception and driving experience among novice drivers. Accident Analysis \& Prevention, 38, 407-414. 
Slovic, P., Fischhoff, B. \& Lichtenstein, S. (1980). Facts and fears: Understanding perceived risk. In Schwing, R. C. \& Albers, W. A. (Eds.) Societal risk assessment. How safe is safe enough? New York: Plenum Press.

Summala, H. (2007). Towards understanding motivational and emotional factors in driver behaviour: comfort through satisficing. In Cacciabue, P. C. (Ed.) Modelling Driver Behaviour in Automotive Environments, Springer Verlag. 189-207.

Taylor, D.H. (1964). Drivers' galvanic skin response and the risk of accident. Ergonomics, 7, 439-451.

Tieliikennelaki [Traffic law], Finland. 267/1981, Chapter 2, 8 §. Retrieved from https://www.finlex.fi/fi/laki/ajantasa/1981/19810267\#L2P8

Underwood, G. (2007). Visual attention and the transition from novice to advanced driver. Ergonomics, $50,1235-1249$.

Vansteenkiste, P., Linus, Z., Greet, C. \& Lenoir, M. (2013). A hazard perception test for cycling children: an exploratory study. Proceedings of the 2013 Conference on Eye Tracking South Africa, ACM. 80-80.

Wallis, T.S.A. \& Horswill, M.S. (2007) Using fuzzy signal detection theory to determine why experienced and trained drivers respond faster than novices in a hazard perception test. Accident Analysis and Prevention, 39, 1177-1185.

Wetton, M.A, Hill, A. \& Horswill, M.S. (2011). The development and validation of a hazard perception test for use in driver licensing. Accident Analysis and Prevention, 43, 1759-70.

Wikman, A.-S., Nieminen, T. \& Summala, H. (1998). Driving experience and time-sharing during in-car tasks on roads of different width. Ergonomics, 4, 358-372.

Wilde, G.J.S. (1984). The theory of risk homeostasis: Implications for safety and health. Risk Analysis, 2, 209-225. 
Supplementary material for Esko Lehtonen, Ville Havia, Anna Kovanen, Miika Leminen, Emma Saure. Evaluating bicyclists' risk perception using video clips: comparison of frequent and infrequent city cyclists. Transportation Research Part F: Traffic Psychology and Behaviour.

Corresponding author: esko.lehtonen@helsinki.fi

\section{Translated instructions}

Instruction 1: You will see video clips that are filmed from the view of a cyclist. Try to imagine being the cyclist depicted and try to observe the situation from the view of the cyclist.

Remember, you should keep your head as still as possible while watching the videos, and move only your eyes. There is a short break after each video and the next video clip will start when you press the space bar on the keyboard.

Instruction 2: You will see video clips that are filmed from the view of the cyclist. Try to imagine being the cyclist depicted and try to observe the situation from the view of the cyclist. During the videos express continuously with the slider the level of caution the situation requires from the cyclist. The bottom of the slider indicates that there is nothing visible that requires special caution from the cyclist. The more the situation requires caution the higher you should move the slider. The top position of the slider indicates that the situation requires perfect concentration in order to avoid falling, colliding or encountering any other danger. Return the slider to the lowest position between the video clips.

Remember, you should keep your head as still as possible while watching the videos, move only your eyes. Do not lift your hand off the slider during the videos. There is a short break after each video and the next video will start when you press the space bar on the keyboard. 


\section{Supplementary Table 1}

Frequent and infrequent cyclists' cycling season during last two years.

\begin{tabular}{lccc}
\hline & All year & $\begin{array}{c}\text { Snowless time } \\
\text { (eg. spring-autumn) }\end{array}$ & Just summer \\
\hline Frequent & 8 & 11 & 0 \\
Infrequent & 1 & 4 & 14 \\
\hline
\end{tabular}

\section{Supplementary Table 2}

Frequent and infrequent cyclists' latest cycling time (the measurement was done from December till January).

\begin{tabular}{lcccc}
\hline & $\begin{array}{c}\text { Less than } \\
\text { week ago }\end{array}$ & $\begin{array}{c}\text { Less than } \\
\text { month ago }\end{array}$ & $\begin{array}{c}\text { More than } \\
\text { month ago }\end{array}$ & $\begin{array}{c}\text { More than half a } \\
\text { year ago }\end{array}$ \\
\hline Frequent & 7 & 6 & 5 & 1 \\
Infrequent & 0 & 0 & 5 & 14 \\
\hline
\end{tabular}

\section{Supplementary Table 3}

Frequent and infrequent cyclists' cycling accidents (eg. falling, collision) during the last two years.

\begin{tabular}{lccc}
\hline & Never & $\mathbf{1 - 5}$ times & Over $\mathbf{5}$ times \\
\hline Frequent & 8 & 9 & 2 \\
Infrequent & 17 & 2 & 0 \\
\hline
\end{tabular}

\section{Supplementary Table 4}

Frequent and infrequent cyclists' amount of driver's licences.

\begin{tabular}{lcccc}
\hline & $\begin{array}{c}\text { A } \\
\text { (motorcycle) }\end{array}$ & $\begin{array}{c}\text { B } \\
\text { (motor vehicle) }\end{array}$ & $\begin{array}{c}\text { C } \\
\text { (large goods vehicle) }\end{array}$ & $\begin{array}{c}\text { AM/M } \\
\text { (moped) }\end{array}$ \\
\hline Frequent & 4 & 17 & 1 & 1 \\
Infrequent & 1 & 14 & 0 & 1 \\
\hline
\end{tabular}

\section{Supplementary Table 5}

Frequent and infrequent cyclists' amount of car/motorcycle driving in Helsinki downtown area during the last two years.

\begin{tabular}{lcccc}
\hline & Never & $\mathbf{1 - 1 0}$ times & $\mathbf{1 1 - 5 0}$ times & Over $\mathbf{5 0 ~ t i m e s ~}$ \\
\hline Frequent & 6 & 3 & 6 & 2 \\
Infrequent & 2 & 10 & 1 & 1 \\
\hline
\end{tabular}

